\title{
TierRAs COMUNALES, REGULACIÓN AGRARIA Y EL COSTUMBRE EN LA CAÑADA DE los Once Pueblos en Michoacán a principios del siglo XXI
}

\author{
Communal Lands, Agrarian Regulation and el Costumbre in La Cañada \\ de los Once Pueblos, Michoacán, at the Beginning of the 2lst Century
}

\author{
María del Carmen Ventura-Patiño*
}

DOI: http://dx.doi.org/10.29043/liminar.vl7i2.681

\begin{abstract}
Resumen: A partir de un trabajo etnográfico se da cuenta de cómo las comunidades p’urhépechas de La Cañada de los Once Pueblos en Michoacán regulan sus tierras, de acuerdo con lo que denominan el costumbre, así como sus tensiones con lo que establece la Ley Agraria, distinguiendo la naturaleza jurídica entre las comunidades agrarias de derecho y de hecho. En las primeras se encuentran procesos que denominamos de "normatividad negociada", mientras que en las segundas se observa mayor autonomía comunal y menor injerencia del Estado en la regulación de sus tierras. A través de sus prácticas comunales cuestionan la idea monista del Estado y reivindican su inclusión como sujetos colectivos, al tiempo que reclaman el reconocimiento de la propiedad comunal de sus tierras y la resolución de sus conflictos de límites. Los programas de certificación y la renta de sus tierras por parte de agroempresas son parte de los actuales desafíos que ponen a prueba sus prácticas de autonomía comunal y su permanencia como colectividades.
\end{abstract}

Palabras clave: comunidades agrarias, ciudadanía comunal, tierras; el costumbre.

Abstract: Based on extensive ethnographic fieldwork, this article seeks to explain how P'urhépecha communities in the region called the Cañada de los Once Pueblos in Michoacán regulate their lands in accordance with what they call el costumbre (customs), as well as the tensions and imbrications that arise in relation to the terms established in agrarian law. To do so, we contrast the juridical natures of legal and de facto agrarian communities, where the former reflect what we call "negotiated normativity", while in the latter we observed greater communal autonomy and less influence by the state in regulating people's lands. Through their communal practices, local indigenous people challenge the monist idea of the state while striving to defend their inclusion in it as collective subjects, simultaneously demanding recognition of their communal property system and their own means of settling boundary conflicts. Certification programs and agreements to lease lands to agribusinesses are two of the challenges that today are testing local practices of communal autonomy and the communities' permanence as collectivities.

Keywords: agrarian communities, communal citizenship, lands, el costumbre.

\footnotetext{
* María del Carmen Ventura Patiño. Doctora en Ciencias Sociales con especialidad en Antropología Social, por el CIESAS-Occidente, México. Profesora-investigadora de El Colegio de Michoacán, México. Temas de especialización: movimiento indígena, territorio, derechos indígenas y políticas agrarias. Correo electrónico: ventura@colmich. edu.mx. ORCID: http://orcid.org/0000-0001-6110-6835.
}

Enviado a dictamen: 24 de septiembre de 2018. Aprobación: 7 de marzo de 2019. Revisiones: 1 . 


\section{introducción}

E n las últimas tres décadas han aparecido algunos estudios que dan cuenta de los desfases y tensiones entre las reglas de acceso y apropiación de la tierra generadas en el ámbito local, por una parte, y la normatividad agraria impuesta por el Estado, por otra. Estos trabajos, en los que se habla de "normatividades paralelas" (Léonard, Quesnel y Velázquez, 1998), "resignificación de proyectos estatales" (Velázquez, 2006) o "pluralidad normativa" (Torres, 2014), se refieren exclusivamente a la tenencia de la tierra ejidal tanto entre poblaciones mestizas, como indígenas. Son escasos los estudios en los que se analizan en profundidad otras formas de tenencia, como la comunal y la privada, existentes entre los pueblos indígenas. Algunas de estas investigaciones se han centrado principalmente en estudiar la conformación histórica de las comunidades agrarias y las tensiones entre el derecho agrario y el derecho indígena (López, 2002). En este trabajo trato de abonar al análisis sobre la normatividad interna de comunidades agrarias con población indígena, en particular sobre las denominadas comunidades de hecho, que han sido poco exploradas, y sobre sus tensiones e imbricaciones con las leyes estatales en materia agraria. ${ }^{1}$

La singularidad y complejidad de la zona de estudio, La Cañada de los Once Pueblos en Michoacán, reside en que en ella hay comunidades agrarias de derecho y de hecho. A pesar de su diferente situación jurídica, ambos tipos comparten una serie de figuras de autoridad, criterios de membresía y formas de acceso y transmisión de derechos que no necesariamente corresponden con las establecidas en la legislación agraria. Estas autoridades y prácticas son resultado de procesos históricos de apropiación, interpretación y resistencia de distintas legislaciones y formas de propiedad y de organización política que se les han intentado imponer a lo largo del tiempo. No se trata de prácticas tradicionales "puras", sino de una imbricación, una especie de palimpsesto sobre el cual pueden encontrarse huellas de formas de organización colonial, pero también normas locales acordes con los nuevos retos que enfrentan las comunidades en su búsqueda por permanecer como colectividades y mantener el control de su regulación interna, aunque no libre de conflictos y contradicciones. Las normas comunales a las que me refiero son una construcción social, en las que la legitimidad es un aspecto fundamental para el ejercicio de gobierno y para el cumplimiento de los acuerdos. Los miembros de las comunidades tienen una particular concepción de propiedad y posesión. La propiedad es colectiva, pero la posesión es individual, el reconocimiento de la posesión implica un estatus de "dueño", aunque con las restricciones definidas en cada comunidad; es decir, hay una "propiedad efectiva" con acceso a recursos (Verdery, 2003, citado en Sikor y Lund, 2009), pero de manera controlada.

El Estado, a través de sus distintas burocracias agrarias, tiene una injerencia acotada y contradictoria. Como bien apuntan Sikor y Lund (2009), las relaciones de propiedad en contextos poscoloniales son ambiguas y flexibles. Las comunidades de estudio regulan sus tierras con cierto margen de autonomía, pero al mismo tiempo contribuyen a la construcción de una "idea de Estado" (Nuijten, 2003) a partir de dos procesos: 1) cuando apelan a sus instituciones agrarias para que les reconozcan la propiedad comunal de sus tierras, y 2) para que diriman a su favor los añejos conflictos de límites con los núcleos agrarios vecinos.

\section{Comunidades agrarias de derecho y de hecho}

Según datos oficiales de 2017, en el país existen 32121 núcleos agrarios -29 728 ejidos y 2393 comunidades agrarias-, de los cuales han sido certificados 30411 . $^{2}$ Entre los núcleos agrarios pendientes de certificar -1289 ejidos y 421 comunidades - se encuentran los que abiertamente han rechazado los programas PROCEDE y FANAR, ${ }^{3}$ pero también los que cuentan con alguna problemática agraria como conflictos de linderos, censos comunales sin actualizar o que carecen de carpeta básica (Resolución Presidencial, acta de posesión y deslinde y plano definitivo), situaciones legales que impiden su certificación. A estas últimas se les denomina comunidades de hecho; por ende, las que sí 
cuentan con esta documentación y han sido ejecutadas sus Resoluciones Presidenciales son reconocidas como comunidades de derecho.

En el anterior artículo 27 constitucional y sus leyes secundarias (1917-1971) se reconocía a las comunidades de hecho: "los núcleos de población que de hecho o por derecho guarden el estado comunal, tendrán capacidad para disfrutar en común las tierras, bosques y aguas que les pertenezcan o que les hayan restituido o restituyeren" (fracc. VI y VII del artículo 27). Aunque no fueron comprendidas en la nueva legislación de 1992, las comunidades de hecho siguen teniendo un respaldo jurídico en la propia Carta Magna, en su artículo 107, que los artífices de la contrarreforma agraria afortunadamente no derogaron. A la letra dice:

Cuando se reclamen actos que tengan o puedan tener como consecuencia privar de la propiedad o de la posesión y disfrute de sus tierras, aguas, pastos y montes a los ejidos o a los núcleos de población que de hecho o por derecho guarden el estado comunal [...] deberán recabarse de oficio todas aquellas pruebas que puedan beneficiar a las entidades o individuos mencionados [...] tampoco procederán desistimiento ni el consentimiento expreso de los propios actos, salvo que el primero sea acordado por la Asamblea General o el segundo emane de ésta $\left[\ldots . .{ }^{4}\right.$

La Suprema Corte de Justicia de la Nación establece en una tesis jurisprudencial:

[...] por comunidad de derecho el Constituyente quiso referirse a aquellos grupos de indígenas que vieron confirmada su posesión por los reyes de España durante la época colonial, o que recibieron tierras durante el proceso de concentración de los indios dispersos, en pueblos, durante dicha época, o que por cualquier otro título tuvieran reconocido su derecho a determinadas tierras, bosques y aguas; y atribuyó existencia jurídica a las comunidades de hecho, al reconocerles existencia jurídica constitucional a las posesiones respetadas por los monarcas españoles, aun cuando no tuvieran título, o a aquellas posesiones que a partir de la conquista adquirieron algunos pueblos [...] el aceptar la tesis de una tercera categoría de comunidades, sin personalidad para comparecer ante una autoridad judicial, es regresar al estado que guardaban las comunidades en el periodo comprendido entre la consumación de la Independencia y la Constitución de 1917 y que se agravó por la ley de 25 de junio de 1856 [...] y si la norma fundamental no distingue, el intérprete tampoco puede hacer distinción. ${ }^{5}$

Por tanto, las instancias judiciales y agrarias deben considerar estas disposiciones al emitir sus sentencias, como lo sostiene la Suprema Corte de Justicia de la Nación: "[...] ya que se trata de bienes jurídicos tutelados por un régimen jurídico constitucionalmente privilegiado". ${ }^{6}$

Así, las comunidades de hecho cuentan con personalidad jurídica, y con ese carácter pueden representarse ante terceros. A más de dos décadas de la creación de nuevas instituciones agrarias responsables de atender el rezago agrario y administrativo, aún existen en nuestro país núcleos agrarios de hecho. La diferencia con las comunidades de derecho es que aún no cuentan con la carpeta básica o una sentencia emitida por los actuales Tribunales Unitarios Agrarios, documentos en los que se establece lo que denominamos datos fundantes: acción agraria, origen de las tierras, si cuentan o no con documentos coloniales que acrediten la propiedad, superficie, ubicación y coordenadas geográficas, colindancias, número y nombre de los sujetos agrarios, así como el plano de sus tierras. Por ello, son núcleos que no pueden ser certificados hasta que cuenten con dicha documentación y haya sido ejecutada la Resolución Presidencial o bien la sentencia del Tribunal Unitario Agrario.

En La Cañada, la regulación de las tierras de las comunidades de hecho está en control de sus miembros y de sus instancias de decisión. También lo están los criterios de membresía, la asignación y transmisión de las tierras, las formas y criterios de elección de sus autoridades comunales y los mecanismos de resolución de conflictos internos, que se rigen por lo 
que denominan el costumbre. Ello significa que tienen un mayor margen de autonomía que las comunidades de derecho para determinar su vida interna, en virtud de que no existe una legislación específica que las norme, de modo que hay una menor intervención del Estado en esta materia; puede afirmarse que existe una "autonomía comunal" para la regulación de las tierras. Sin embargo, también se observa que en la mayoría de las comunidades de derecho analizadas el costumbre es importante para regular su vida colectiva, incluyendo las tierras. El costumbre se refiere al conjunto de normas y principios que buscan regir la vida comunal en todos sus ámbitos; es definido, reelaborado y resignificado por los miembros de la comunidad a través del tiempo, como resultado de procesos históricos de apropiación y resistencia a diferentes órdenes políticos y jurídicos.

La diferencia principal respecto a el costumbre en ambos tipos de comunidades estriba en que en las de derecho las instituciones agrarias están más presentes, por ejemplo, en la elaboración de los censos, en la elección del Comisariado de Bienes Comunales, o en la inscripción ante el Registro Agrario Nacional de actos agrarios relativos a creación, modificación o extinción de derechos, entre otros, para que tengan validez jurídica. $\mathrm{Al}$ respecto, sostengo que en estas comunidades se da un proceso de "normatividad negociada", esto es, se rigen bajo el costumbre para su vida interna, pero cuando requieren del reconocimiento legal de sus actos agrarios recurren a las instituciones agrarias.

\section{Apropiación de la ley y el costumbre}

En Michoacán la propiedad social comprende poco más de la mitad del territorio estatal, distribuido en 1754 ejidos $^{7}$ y 135 comunidades, ${ }^{8}$ más las comunidades de hecho. ${ }^{9}$ La Cañada es una de las cuatro subregiones que forman parte de la región p'urhépecha. Diez de las comunidades de estudio pertenecen al municipio de Chilchota y otra más, Etúcuaro, al municipio de Tangancícuaro. Estas comunidades son a su vez localidades submunicipales, cuyas cabeceras municipales están habitadas en su mayoría por mestizos.
Las comunidades que no cuentan con carpeta básica son: Carapan, Huáncito, Zopoco, Urén, Ichán y Tacuro. De las cinco que tienen carpeta básica, tres ya fueron certificadas: Chilchota, Santo Tomás y Etúcuaro (ver Cuadro 1). Sin embargo, todas ellas tienen conflictos agrarios, una por posesión y todas por límites (ver Cuadro 2). Las comunidades de hecho no han dejado de solicitar ante las instituciones agrarias - antes Secretaría de Reforma Agraria, ahora Tribunales Unitarios Agrarios- el reconocimiento de la propiedad de sus tierras, por lo que todas ellas tienen un procedimiento en curso o pendiente. Algunos de los procesos jurídicos se han prolongado cerca de un siglo; innumerables han sido los oficios y documentos que han entregado a las distintas burocracias agrarias con la esperanza de obtener la carpeta básica. Por ejemplo, en el contexto de la Ley Agraria del 6 de enero de 1915, la comunidad de Ichán inició en 1917 los trámites para la restitución de sus tierras. Desde entonces han realizado gestiones ante las distintas instituciones agrarias tanto para lograr el reconocimiento de la propiedad de las tierras que poseen, como para la resolución del conflicto de límites que sostienen con la comunidad vecina de Tacuro desde 1925. Dicho conflicto sigue vigente hasta el año 2018, como lo están también todos los conflictos de límites del resto de las comunidades de La Cañada.

En ese sentido, como bien afirma Nuijten (2003), las comunidades también contribuyen a la construcción de una idea de Estado, en este caso, cuando apelan a su intervención para que se les reconozca la propiedad comunal de sus tierras, pero también cuando solicitan la mediación oficial para que resuelvan a su favor los añejos conflictos de límites que sostienen con las comunidades vecinas. Como puede observarse en los Cuadros 1 y 2, seis son comunidades de hecho, pero todas tienen conflictos de límites. Las comunidades con Resoluciones Presidenciales ejecutadas las obtuvieron por dos razones: 1) por haber aceptado que se les reconociera sólo la superficie sin conflicto, y 2) por estar de acuerdo en dirimir tales conflictos a través de los juicios correspondientes, aunque muchos de éstos se encuentran sin avance procesal desde hace varios años. 
Estos conflictos tienen sus propios ciclos; se reactivan de vez en cuando, generando tensión $y$ en ocasiones enfrentamientos, y cuando esto sucede solicitan la intervención de las instituciones gubernamentales para que definan los linderos. Sin embargo, el panorama es complejo puesto que todas dicen tener el derecho sobre las tierras en disputa y exigen que las resoluciones o sentencias se dicten en tal sentido. Estos conflictos agrarios forman parte del programa gubernamental Focos Rojos, creado en 2003 durante la administración de Vicente Fox, llamado Programa de Atención a Conflictos Sociales en el Medio Rural (COSOMER) desde 2006. Diseñado para atender la conflictividad agraria en el país, en particular para aquellos lugares donde hubo hechos de violencia - enfrentamientos y muertes - que pusieron en serio riesgo la gobernabilidad y en los que se agotó la vía jurídica sin obtener resolución (Reyes, 2004). De los catorce focos rojos detectados en el país, uno de ellos comprende la Meseta P'urhépecha, que a su vez contempla cerca de sesenta asuntos, incluidos los de La Cañada (Ventura, en prensa).

\section{Entre la legalidad y la legitimidad}

En su estudio realizado en La Cañada en relación con la tenencia de la tierra, Moisés Franco señala que actúan dos fuerzas, lo que él denomina "la costumbre" y la ley. La primera la entiende como "una manera de actuar obligatoria, practicada y aceptada por la generalidad en forma espontánea" (Franco, 1997: 18), mientras que la segunda emana del exterior, es decir, es elaborada lejos y fuera del contexto particular de las comunidades. En este trabajo interesa mostrar cómo coexisten la ley y el costumbre en la regulación de las tierras comunales, la manera en que la primera es apropiada e interpretada y las posibles imbricaciones o tensiones que surgen en su interacción. Se tratará de dar cuenta de lo anterior a través de exponer: 1) cuáles son las autoridades comunales encargadas de atender los asuntos relacionados con la tierra, 2) la definición de los criterios de membresía y las tensiones entre sujeto agrario y comunero, y 3 ) los derechos de los comuneros sobre las tierras, que expresan sus concepciones de propiedad y posesión.

\section{a) Autoridades comunales, una forma particular de gobierno comunal}

En las comunidades de estudio, aparte de las autoridades civiles y agrarias existen las autoridades tradicionales, incluidas las religiosas. En la práctica comunal no sólo se da una convivencia, sino una imbricación entre ellas, al ejercer funciones y facultades no necesariamente establecidas en la ley; esto es lo que denominamos "gobierno comunal".

Conforme a la Ley Orgánica Municipal, ${ }^{10}$ en Michoacán el jefe de tenencia es el enlace del ayuntamiento con la localidad submunicipal, aunque en las comunidades más bien cumple con las funciones de representar a éstas ante el ayuntamiento. Entre sus funciones estipuladas por la ley se encuentran las de resguardar el orden público y gestionar la realización de obras públicas. En algunas comunidades aún existen los jueces de tenencia, quienes pertenecían a la estructura del Poder Judicial de Michoacán, instancia que, de acuerdo con la ley, era la encargada de nombrarlos, aunque en la práctica eran designados por la comunidad. En 2005 el Congreso local acordó por decreto su desaparición. Sin embargo, algunos jueces siguen ejerciendo justicia en sus comunidades, además de cumplir con funciones agrarias y religiosas, entre las que se encuentran: resolver conflictos entre familiares o vecinos, atender asuntos menores y notificar a las autoridades municipales los hechos de violencia mayores y, de participar de manera activa en los ciclos festivos.

Según la Ley Agraria, el Comisariado de Bienes Comunales -integrado por: un presidente, un secretario y un tesorero, propietarios y suplentes- y el Consejo de Vigilancia -integrado por: un presidente y dos secretarios, propietarios y suplentes- constituyen los órganos de representación de cada comunidad y son los encargados de conocer todos los asuntos relacionados con las tierras - solares, cerros y tierras de cultivoSus integrantes deberán ser comuneros legalmente 
reconocidos, haber trabajado en la comunidad durante los últimos seis meses y no haber sido sentenciados por delito intencional que amerite pena privativa de la libertad. Serán electos en asamblea con voto

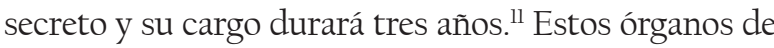
representación corresponden a las comunidades de derecho; para las comunidades de hecho, en la anterior legislación se señalaba la conformación de un Comité Particular Ejecutivo -integrada por un presidente, un secretario y un vocal, con sus respectivos suplentes miembros del grupo solicitante -,${ }^{12}$ encargado de las gestiones ante dependencias agrarias, ya sea para la restitución, el reconocimiento o la titulación de los bienes comunales.

Aparte de las autoridades mencionadas que llamaremos oficiales, coexisten en las comunidades otras instancias -incluido el sistema de cargos responsable del ámbito religioso, del que no se tratará aquí- como el Ayuntamiento, el Cabildo y el Consejo, que denominaremos autoridades tradicionales, cuyos nombres refieren a instituciones coloniales. Todas ellas participan en el ejercicio del gobierno comunal conociendo y deliberando sobre los asuntos de mayor trascendencia. Sus integrantes son nombrados a través de distintos mecanismos. En la regulación de tierras, las autoridades oficiales y tradicionales atienden los asuntos, y sus funciones y facultades se encuentran imbricadas entre lo que establecen la ley y el costumbre. Veamos un ejemplo.

Acachuén es una comunidad de derecho, por tanto, cuenta con su Comisariado de Bienes Comunales y su Consejo de Vigilancia como establece la Ley Agraria; sin embargo, sus funciones las comparten con el jefe de tenencia y el denominado Ayuntamiento nombrado por la comunidad, que es distinto del municipal, de modo que es una instancia no contemplada en ninguna legislación. El Ayuntamiento, que llamaremos comunal, está integrado por catorce comuneros — seis por cada uno de los dos barrios y dos por la colonia-, que permanecen en el cargo un año, al igual que el jefe de tenencia. Todos son propuestos por los barrios y nombrados en asamblea general a través de votación directa y abierta, levantando la mano. Al jefe de tenencia le corresponde atender los asuntos de los solares, facultad que no está considerada en la Ley Orgánica Municipal, mientras que los asuntos de las parcelas y del cerro son atendidos por el Comisariado de Bienes Comunales y el Consejo de Vigilancia. De esta forma, sus ámbitos de competencia se encuentran imbricados. En caso de conflicto ambas autoridades están presentes en las reuniones. Si éste es sobre solares, el jefe de tenencia dirige la sesión junto con su Ayuntamiento, y si se trata de parcelas o del cerro, los responsables son el Comisariado de Bienes Comunales y el Consejo de Vigilancia. Todos ellos estampan firmas y sellos en los documentos elaborados, los cuales tienen validez al interior de la comunidad, y en caso de controversia pueden ser considerados por las instituciones agrarias como documentos de prueba.

Entonces, el Comisariado de Bienes Comunales, el Consejo de Vigilancia, el jefe de tenencia y el Ayuntamiento comunal conocen de los asuntos más importantes de la comunidad; ellos constituyen, junto con el sistema de cargos religiosos, las instituciones del "gobierno comunal". De esta manera se cumple con lo que señala la ley, pero a la vez hay un proceso de adaptación a las propias formas de organización social de las comunidades, lo que les permite tener el control y la regulación de sus tierras, e incluso cuentan con un reglamento interno que ellas elaboraron sin intervención de funcionarios agrarios. ${ }^{13}$

A continuación revisaré cómo se organiza una comunidad de hecho. El caso de Huáncito es por demás interesante. A pesar de no contar con carpeta básica, decidieron nombrar el Comisariado de Bienes Comunales y el Consejo de Vigilancia. Al presidente del primero, que llaman "representante", le corresponde atender lo relacionado con las tierras parceladas y el cerro, junto con los demás integrantes de las dos instancias. Éstos, junto con el jefe de tenencia y los miembros de lo que llaman Consejo, instancia parecida al Ayuntamiento comunal de Acachuén, discuten y resuelven los asuntos de mayor trascendencia y se acompañan en las gestiones. La forma en que nombran al "representante" - presidente del Comisariado de Bienes Comunales - es la siguiente: 
Aquí siempre se han hecho por usos y costumbres [...] cuando es la elección de autoridades se forman dos barrios nada más [...] entonces, cada Barrio 'ora sí que propone a uno; el que tenga más votos, ese es el propietario, y el que no, de todos modos queda de suplente [...] Nada más levantando la mano. ${ }^{14}$

El Consejo lo forman entre ocho y diez personas por cada uno de los seis cuarteles y se nombran en Semana Santa: "al acabar la procesión ya hay mucha gente ahí, y ahí empiezan a decir 'vamos a formar a la persona que va a ir al Consejo"'. ${ }^{15}$ Son personas mayores que han ocupado algún cargo civil o agrario y se les denomina sesi jánhaskaticha, ${ }^{16}$ "son los sabios, los mayores". En Huáncito todavía existe el juez de tenencia, quien fue nombrado en asamblea comunal en 2012; a pesar de que la legislación no lo reconoce, continúa siendo una autoridad con legitimidad avalada por la comunidad. ${ }^{17}$ Al juez le compete conocer los asuntos sobre conflictos menores y la organización de las fiestas religiosas como a algunos otros jueces de la región p'urhépecha, pero también atiende lo relacionado con los solares: "yo atiendo aquí con todos los terrenos, yo conozco todas las tierras, pero en función mía es quinientos metros al pueblo, retirado, es todo. De la iglesia quinientos metros". ${ }^{18}$ Entonces, si el asunto se refiere a solares, el juez lleva la responsabilidad de la reunión; él habla y elabora ya sea la minuta o el testamento correspondiente. El "representante" o el jefe de tenencia están presentes, respaldan su voz si es necesario y también firman y sellan el documento que se elabore en calidad de testigos. Una situación similar sucede cuando el "representante" lleva la reunión; los demás están presentes y firman y sellan los documentos elaborados por el primero. Todos ellos han ocupado distintos cargos civiles, agrarios y religiosos, son reconocidos por su participación y servicio a la comunidad, "son hombres de respeto"; en este sentido, el prestigio derivado del servicio es importante para el nombramiento de las autoridades comunales. Ellos forman parte de lo que he llamado "gobierno comunal", que no necesariamente corresponde a lo estipulado en la legislación. Es más, desafían a través de sus prácticas lo decretado por el Poder Legislativo que ya es inoperante, como en el caso de los jueces; por tanto, la legitimidad de las normas locales, construidas comunalmente a través del tiempo, es más importante que el cumplimiento de la legalidad en la regulación de su vida comunal: a mayor fortalecimiento de su gobierno comunal, mayor autonomía interna y menor intervención del Estado en sus asuntos.

En el resto de las comunidades de La Cañada pueden encontrarse formas organizativas que muestran esta capacidad de adaptación; por ejemplo, en las otras comunidades de derecho y de hecho las autoridades agrarias también trabajan de manera coordinada con el jefe de tenencia, el juez y las llamadas autoridades tradicionales: como con el Consejo comunal (Carapan), el Cabildo (Ichán) o el Ayuntamiento (Ichán y Tacuro). Conforman junto con otras instituciones su propio gobierno comunal, entendido como una imbricación particular de instituciones civiles, agrarias, judiciales, religiosas y tradicionales, resultado de procesos históricos de apropiación y resistencia a distintos órdenes políticos y jurídicos, como un palimpsesto construido a través del tiempo.

\section{b) Criterios de membresía. Sujeto agrario y comunero}

En la Ley Agraria no se especifica cómo se adquiere la calidad de comunero, pero de acuerdo con el artículo 107: "Son aplicables a las comunidades todas las disposiciones que para los ejidos prevé esta ley, en lo que no contravengan lo dispuesto en este Capítulo". En esta dirección, el artículo 15 establece que para adquirir la calidad de ejidatario se requiere: "I. Ser mexicano mayor de edad o de cualquier edad si tiene familia a su cargo o se trate de heredero de ejidatario; II. Ser avecindado del ejido correspondiente, excepto cuando se trate de un heredero, o cumplir con los requisitos que establezca cada ejido en su reglamento interno". Por otra parte, el artículo 16 señala cómo se acredita la calidad de ejidatario: "I. Con el certificado de derechos agrarios expedido por autoridad competente; II. Con el certificado parcelario o de derechos comunes; o III. Con la sentencia o resolución relativa del tribunal agrario". ${ }^{19}$ 
Para el caso de los comuneros, como sujetos agrarios, su calidad se acredita ya sea con el censo que aparece en la Resolución Presidencial o en la sentencia emitida por el Tribunal Unitario Agrario, en la que se reconoce legalmente la existencia de la comunidad agraria, o bien con el censo actualizado expedido por el Registro Agrario Nacional; este último es resultado de la inscripción del acta de asamblea en la que los comuneros legalmente reconocidos decidieron aceptar a otros con esa calidad agraria. Lo anterior corresponde a las comunidades de derecho; en las de hecho los criterios son definidos de acuerdo con sus propias normas, aunque para efectos legales su calidad agraria puede acreditarse con el reconocimiento expedido ya sea por el representante de bienes comunales o por la asamblea. Sin embargo, en la práctica local, tanto en las comunidades de derecho como en las de hecho se presenta una imbricación entre lo que establecen la ley y el costumbre, con sus propias categorías sociales.

En ambos casos, la categoría social de comunero no necesariamente corresponde a la del sujeto agrario definida por la legislación, y no se circunscribe al reconocimiento por parte de las instituciones agrarias, sino que obedece al reconocimiento como miembro de la comunidad por el resto de los integrantes de ésta, una vez que ha cumplido con ciertos requisitos compartidos por la mayoría, aunque tal reconocimiento no está libre de conflictos; la inclusión y exclusión también es un ámbito de disputa. Aun así, todas las comunidades aquí estudiadas comparten la exigencia de varios requisitos: haber nacido en la comunidad, vivir ahí y cumplir con las obligaciones comunitarias. En la mayoría de las comunidades se reconoce como comuneros a los jefes de familia, por lo general a los hombres una vez que se han casado o bien a las viudas o mujeres con familia a su cargo. Además, deben cumplir con las cooperaciones y faenas, tanto las relacionadas con obras de beneficio comunal como las vinculadas con la vida religiosa, y prestar servicio a la comunidad, ya sea por voluntad propia o por mandato de la asamblea o de la autoridad comunal en los cargos civiles, agrarios o religiosos.

En Acachuén, que es una comunidad de derecho, un comunero es:
Ahí ya si tú ya te casaste, si tú ya te robaste o ya te juntaste con la novia o ya la llevaste a tu casa, ahí ya eres un comunero [...], tienes que entrarle a los compromisos de la comunidad: que tú debes de hacer faenas, debes de estar al tanto con las cooperaciones, al pendiente pues, lo de la comunidad [...]. ${ }^{20}$

Estos criterios son muy parecidos a los definidos en Huáncito, que es una comunidad de hecho. Además de ser originario, se adquiere la calidad de comunero: "[...] si tienes 16 años y te casas [...] ya se te asigna un cargo. El primer cargo que uno tiene cuando recién casado [...] es hacer, le dicen 'cabos', son los que se encargan de avisar a la gente [..." ${ }^{21}$

En Carapan, que es una comunidad de hecho, se elaboró un censo en el año 2000 con intervención de funcionarios del Registro Agrario Nacional debido al proceso promovido para regular su situación agraria, en 1997. Esto los obligó a definir criterios para diferenciar a comuneros de sujetos agrarios:

Hay dos tipos de comuneros que le llaman ahí en la comunidad: son los de hecho y los de derecho. Los comuneros de hecho simplemente son los que nacieron aquí [...] los de derecho son los que tienen tierras de la comunidad, que están legalmente registrados [en el Registro Agrario Nacional]. Pero si no tienes tierras, no trabajas, no defiendes el monte, no participas en la defensa, por ejemplo, en algún incendio, ipor qué te vamos a dar la calidad de comunero? [...] primer punto, para ser comunero necesita forzosamente haber nacido en la comunidad y hablar el p'urhépecha [...].22

Si bien todos son comuneros, los considerados en el censo tienen más derechos. En las asambleas empieza a manifestarse esta distinción: los comuneros de hecho tienen derecho a voz, pero no a voto, y tampoco pueden ocupar cargos de representación; lo que avizora un escenario de posibles tensiones. Esto no sucede en las asambleas de las comunidades de hecho, en las que sus miembros tienen los mismos derechos de voz y voto, a excepción de los que no cumplen con 
los criterios definidos comunalmente, pero no por su situación agraria.

Como se ha observado, en las comunidades de hecho los criterios de membresía aluden a una "ciudadanía comunal", son resultado de una construcción social de adscripción que responde a la regulación de la vida comunal y no se restringen a una relación de sujeto agrario/tierra definida y regulada por la legislación agraria, sino a su pertenencia y participación en la vida colectiva, que incluye otros ámbitos como los sociales, religiosos o identitarios. Por su parte, en las comunidades de derecho, si bien sigue existiendo la ciudadanía comunal, con la introducción de la figura de sujeto agrario empiezan a surgir procesos de exclusión que pueden potenciar tensiones intracomunitarias.

\section{c) Derechos, herencia, cesión y renta. Propiedad y posesión}

Respecto a los derechos de los comuneros la Ley Agraria establece:

Artículo 101. La comunidad implica el estado individual de comunero y, en su caso, le permite a su titular el uso y disfrute de su parcela y la cesión de sus derechos sobre la misma en favor de sus familiares y avecindados, así como el aprovechamiento y beneficio de los bienes de uso común [...]. El beneficiado por la cesión de derecho de un comunero adquirirá la calidad de comunero. Cuando no exista litigio, se presume como legítima la asignación de parcelas existentes de hecho en la comunidad.

Artículo 102. En los casos en que no exista asignación de parcelas individuales se presumirán iguales, mientras no se pruebe lo contrario, los derechos correspondientes a los comuneros. ${ }^{23}$

De acuerdo con los criterios de membresía comunal revisados, el cumplimiento de las obligaciones es requisito indispensable para el reconocimiento de la calidad de comunero; sólo así se logra la ciudadanía comunal, de modo que son más importantes las obligaciones que los derechos, como señala el presidente del Comisionado de Bienes Comunales de Acachuén: "Si tú estás cumpliendo con tu comunidad tienes derecho a todo, pero si tú no cumples, no tienes derecho a nada". ${ }^{24}$ Ello no se apega estrictamente a lo que la Ley Agraria establece sobre los derechos de los comuneros legalmente reconocidos.

En general, los derechos de los comuneros consisten en trabajar su parcela y aprovechar los recursos de los cerros, como recoger leña - en algunas comunidades una vez a la semana-, recolectar plantas o llevar a pastar a los animales - la única restricción es que no afecte las siembras-; en la mayoría de las comunidades no se permite cortar árboles, sólo si se requieren para la construcción de una casa o para cumplir los compromisos de un cargo religioso, previo permiso de las autoridades comunales. También tienen derecho de beneficiarse en caso del reparto de solares una vez que se verifique el cumplimiento de sus obligaciones y que la asamblea esté de acuerdo, además de beneficiarse de todos los servicios públicos con los que cuente la comunidad.

En las comunidades de Chilchota (de derecho) y Carapan (de hecho), a los comuneros de hecho, como ellos los nombran, si hay "terreno" se les presta para que siembren. Lo mismo sucede con las otras comunidades; por ejemplo, en Huáncito (de hecho) a los comuneros que no tienen tierra, "cualquiera que quiera ir y limpiar esa parte, lo puede hacer para el usufructo [...] en p'urhépecha le decimos pari akoatakoreni [para que estés comiendo de ahí], pero no para que lo vendas". ${ }^{25}$ Si el comunero no trabaja durante dos años esta tierra comunitaria, a la que se tiene acceso no por ser sujeto agrario sino por ser comunero, la comunidad puede destinarla a otro comunero; en caso de que la trabaje por muchos años puede heredarla, pero en las mismas condiciones, "nada más de prestado", esto es, tiene derecho a sembrar y heredar, pero no a realizar tratos agrarios. Por lo regular, estas tierras que se abren al cultivo se ubican en las faldas de los cerros. Lo anterior muestra que no todos los comuneros tienen tierra, como bien apunta Robles Berlanga (2000) respecto a uno de los mitos sobre las comunidades; no obstante, eso no implica que no gocen del resto de los derechos reconocidos por la ciudadanía comunal siempre y cuando cumplan con sus obligaciones. 
Con relación a la herencia, la legislación establece que, en caso de que no exista designación de sucesores, los derechos agrarios se transmitirán conforme al siguiente orden de preferencia:

Artículo 18 [...] I. Al cónyuge; II. A la concubina o concubinario; III. A uno de los hijos del ejidatario; IV. A uno de sus ascendientes; y V. A cualquier otra persona de las que dependan económicamente de él. [...] si al fallecimiento del ejidatario resultan dos o más personas con derecho a heredar, los herederos gozarán de tres meses a partir de la muerte del ejidatario para decidir quién, de entre ellos, conservará los derechos ejidales. En caso de que no se pongan de acuerdo, el Tribunal Agrario proveerá la venta de dichos derechos ejidales en subasta pública y repartirá el producto, por partes iguales, entre las personas con derecho a heredar. ${ }^{26}$

Enlas comunidades de derecho y de hecho se acostumbra este orden de preferencia. En algunas comunidades de hecho, en caso de que los padres hayan fallecido, al hijo mayor le corresponde realizar el reparto. Si surge un conflicto intervienen las autoridades comunales en su conjunto para conocer y resolver de manera equitativa, o bien puede suceder que la asamblea determine que las tierras pasen a manos de la comunidad. En caso de controversia, las autoridades comunales y la propia asamblea pueden inclinarse a favor de quien consideren que cumple con la comunidad: "estar al corriente" con sus cooperaciones y realizar sus obligaciones, es decir, los criterios de membresía comunal estén presentes.

Revisemos un ejemplo. En la comunidad de Zopoco (de hecho), dos hermanos reclamaron su derecho a la herencia. La hermana se casó con un hombre de la comunidad vecina y reside en Estados Unidos, mientras que el hermano vive en Zopoco y está al corriente con las cooperaciones y faenas. Ante el desacuerdo entre ellos, el hermano solicitó la intervención de las autoridades comunales, quienes convocaron a una asamblea:

[...] entonces la gente dijo [que] le corresponde al muchacho [...] mientras esa persona está cumpliendo con sus obligaciones, él es el que tiene derecho. [...] a quien el pueblo lo reconoce como ciudadano [...]. La muchacha le quiere recoger todos los terrenos a él, y según nuestras costumbres cuando una mujer ya se casó fuera del pueblo, ya no tiene los mismos derechos porque ya vive en la otra comunidad. Y no está en Santo Tomás [comunidad vecina], está en el norte. ${ }^{27}$

En este caso los criterios de la ciudadanía comunal fueron determinantes en la resolución de la asamblea; el reconocimiento de derechos está vinculado no sólo con haber nacido ahí, sino con vivir en la comunidad y cumplir con todas las cooperaciones y faenas. Las autoridades comunales son las encargadas de vigilar el cumplimiento de las obligaciones y, en su caso, aplicar las sanciones correspondientes, mientras la asamblea es la instancia para dirimir los conflictos. Sin embargo, también existe la posibilidad de que alguna de las partes inconformes acuda a otras instancias no comunales. Estos casos de controversia dan cuenta de que la membresía también es materia de disputa por definir sus contenidos entre sus integrantes.

En las comunidades de derecho y de hecho, por lo general los comuneros heredan en vida y por partes iguales a todos los hijos, lo que significa que se fraccionan las parcelas, aunque al hijo mayor se le reconoce como comunero, mientras los otros tendrán que hacer méritos ante la comunidad para ser reconocidos como tales. Cuando el comunero o comunera decide heredar, manifiesta su voluntad ante las autoridades comunales, ya sea el juez, el presidente o el representante del Comisionado de Bienes Comunales, según sea el caso, quienes junto con las otras autoridades tradicionales elaboran, firman y sellan un documento que cuenta con legitimidad y cuya función es regular la transmisión de los derechos. Este proceso es similar en ambos tipos de comunidades, lo que cambia son las denominaciones. En las comunidades de derecho le llaman: acta de posesión en Chilchota, acuerdos de una herencia en Santo Tomás y testamento en Acachuén; y en las de hecho: minuta de cesión de derechos a título gratuito en Carapan, constancia de donación en Huáncito y acta de la última palabra en Zopoco. 
Sobre la cesión, que es un derecho de los comuneros reconocido en la legislación, se encuentran algunas restricciones en las prácticas comunales. En principio, es importante aclarar que, de acuerdo con la ley, en las comunidades no se puede realizar la enajenación, como sí sucede en los ejidos; sólo se puede ceder los derechos a un familiar o a un avecindado. ${ }^{28}$ No obstante, en la mayoría de las comunidades de La Cañada no está permitido que el avecindado sea sujeto de cesión, sólo se puede ceder a otro comunero, como categoría local, o a un familiar. De este modo, hay un control interno sobre la transmisión del derecho.

El presidente del Comisionado de Bienes Comunales y las otras autoridades comunales son las encargadas de realizar la documentación, que también tiene diferentes nominaciones y alcances. Por ejemplo, en Acachuén, comunidad de derecho, se llama título de propiedad, lo que significa que quien adquiere los derechos es "dueño absoluto de la parcela tal, con las siguientes medidas y colindancias", significa "que tú puedes trabajar esas tierras sin que te moleste nadie dentro de la comunidad". Puede vender o rentar, pero a "gente de la misma comunidad", a personas de fuera no, "hay una acta levantada que no hay que permitir eso [...] la asamblea acordó que nadie, nadie se va a meter". ${ }^{29}$ Aunque en la práctica se dan casos que transgreden los acuerdos comunales, en ocasiones las autoridades logran revertir los tratos o sancionar a quienes los incumplen. Por ejemplo, en Huáncito está prohibido vender, sólo se permite el traspaso entre familiares: "se lo estoy dando a mi sobrino [...] a mi hijo o a mi nieto para que lo trabaje, nada más, no es por ninguna cantidad, es nada más para el usufructo". ${ }^{30}$ Sin embargo, en ocasiones se realizan ventas a gente de afuera "a escondidas"; cuando esto sucede, se procede a lo que llaman "expropiar", si es que así lo acuerda la asamblea, se levanta un acta y con este documento se respaldan las autoridades ante cualquier instancia judicial o agraria a la que acuda el comprador: "[...] nosotros, como autoridad, ya sabemos que tienen que regresar; aquí lo que decida la comunidad es lo que se hace [...] ellos a mí, inclusive, me han llamado [Tribunal Unitario Agrario]. Nosotros no podemos [TUA], no somos competentes a eso".31
Sostenemos que las comunidades de hecho tienen un mayor margen en la regulación de sus asuntos internos para definir criterios de membresía, que dan lugar a lo que llamamos una "ciudadanía comunal", para el control de los tratos agrarios y para la organización y funcionamiento de sus autoridades comunales. Al no contar con una carpeta básica, no hay un censo comunal, por ello, no hay comuneros legalmente reconocidos ni parcelas asignadas legalmente, de tal forma que no pueden realizar tratos agrarios de manera oficial. De este modo, en caso de algún litigio los compradores no cuentan con un respaldo jurídico que puedan presentar como prueba ante una instancia judicial o agraria. La instancia facultada para conocer y resolver estos asuntos es la asamblea comunal, a la que asisten todos los comuneros con los mismos derechos, excepto aquellos que incumplen con sus obligaciones. La asamblea es la instancia de la toma de decisiones, lo cual no quiere decir que en ésta no tengan lugar tensiones y disputas. En caso de conflicto, los magistrados de los Tribunales Unitarios Agrarios mandan llamar a las autoridades agrarias comunales para conocer su versión, y en muchos casos regresan el asunto a las instancias comunales, cuya resolución es respaldada por los Tribunales. De este modo, ejercen una cierta autonomía para la resolución de sus asuntos internos; esto es, hay una menor intervención del Estado.

En cambio, en comunidades como Chilchota, que ya fue certificada -únicamente los límites-, los mecanismos de regulación de las tierras se han debilitado:

Las ventas no se valen, pero desgraciadamente se han hecho [...] es un problema muy fuerte en eso de que se han vendido ya a varias gentes, incluso de fuera $[. .$.$] las tierras comunales en sí no son$ negociables ni son pequeñas propiedades [...] pues la gente comunera de hechoy de derecho vendieron. Al final de cuentas, iqué podemos hacer ${ }^{32}$

Incluso, algunos comuneros acudieron a notarios de la ciudad de Zamora para realizar tratos agrarios 
de este tipo, pero la comunidad considera que las escrituras así obtenidas no tienen validez, de manera que no reconocen tales cesiones en caso de conflicto, como tampoco tienen fundamento jurídico si llegara a presentarse alguna controversia en una instancia judicial o agraria.

En particular, la renta de tierras a empresas agrícolas ha puesto en riesgo el control de las tierras en las comunidades de derecho y de hecho. En Huáncito y Acachuén aún mantienen el control restringiendo la renta entre los propios comuneros, pero en otras comunidades que han rentado superficies importantes a empresas agrícolas, estas últimas han actuado sin consentimiento de la asamblea con acciones como cerrar caminos, borrar mojoneras o talar árboles. Por ejemplo, en Carapan algunas personas están rentando sus parcelas a tres compañías por varios años, comprenden una superficie aproximada de quinientas hectáreas. En Ichán sucede algo similar; a pesar de que la asamblea determinó que no se rentara, algunas personas lo hicieron con la participación de un representante anterior:

[...] porque la asamblea determinó de que no se rentara [...] Pero como ya no se trabajaba por allá o los cultivos que se hacían ya no producían, pues vieron muy atractiva la cantidad y desobedecieron a la asamblea. Se le encargó al representante [...] que hiciera un acta y se la entregara a la empresa de que no podría rentar; pero es por ahí cuando se hizo el cambio que hubo manejos por debajo del agua.. ${ }^{33}$

De igual forma ocurre en Santo Tomás, comunidad que, a diferencia de Chilchota y Etúcuaro, en 2011 midió y certificó su zona parcelada; después, casi de inmediato rentaron sus tierras a una empresa productora de berries. ${ }^{34}$ Aunque algunos comuneros ya están arrepentidos, tienen que esperar a que termine el plazo de diez años. Para ellos, el hecho de que sus tierras se midieran y recibieran un certificado parcelario ha significado que ya pueden disponer libremente de ellas. En este sentido, la concepción de propiedad individual empieza a permear sobre la concepción comunal, a pesar de que legalmente continúa siendo un régimen de propiedad comunal.

Como se ha observado, las rentas muestran que los mecanismos de regulación comunal no siempre son lo suficientemente sólidos tanto en las comunidades de derecho, como en las de hecho. La observancia de la ley, junto con el cumplimiento de los acuerdos comunales, depende principalmente de la cohesión comunal y de la legitimidad que los comuneros den a dichos acuerdos, así como de las instituciones encargadas de su vigilancia. Sin embargo, como bien advierte Broegaard (2009), las políticas neoliberales que buscan privatizar las tierras pueden contribuir a agravar los conflictos y a minar la legitimidad de las autoridades.

Sobre la concepción de propiedad y posesión, Moisés Franco sostiene que "la visión cultural del p'urhépecha respecto a la tierra equivale a decir: 'poseemos la tierra porque somos propietarios' o de otra forma, 'somos propietarios porque ocupamos la tierra"' (Franco, 1997:35). Considero que esta concepción de propiedad-posesión de alguna manera sigue vigente.

Desde la concepción comunal se regula el acceso a la tierra, además de su uso, aprovechamiento, transmisión, o bien separación. Las tierras son propiedad comunal, esto es, los dueños son todos los comuneros; en ese sentido, actúan como corporación frente a otros y existe un fuerte sentimiento de pertenencia que se expresa claramente en los casos de conflictos de límites. Pero se observa también una apropiación individual a través de la posesión de las tierras de cultivo, que se fueron adquiriendo principalmente por cesión - a título gratuito o monetario-, herencia o asignación de la asamblea, por lo que la distribución de tierras no es equitativa y puede haber concentración en algunas familias que, por lo regular, son las más acomodadas $y$, en algunos casos, las que han ocupado cargos de representación.

La posesión confiere derechos que son reconocidos por el resto de los miembros de la comunidad al uso, usufructo y disfrute de la tierra, o a celebrar actos como cesión, herencia o renta, con las restricciones acordadas en cada comunidad. Así, las posesiones 
son resultado de las distintas modalidades de acceso y transmisión que han tenido lugar a lo largo de la historia de la comunidad, es decir, que no ha habido una delimitación ni una asignación legalmente reconocida o avalada a través de un documento expedido por las instancias agrarias gubernamentales. Como el reconocimiento de la comunidad es importante en la regulación de las tierras, éste recae en las autoridades comunales asignadas para conocer de estos asuntos, quienes tienen la responsabilidad y la facultad para expedir documentos que amparen la posesión y los tratos agrarios realizados en el marco de los acuerdos comunales. Incluso, las autoridades comunales no sólo cuentan con la legitimidad de la comunidad, sino también son reconocidas y consultadas en las controversias que se dirimen ante instancias judiciales y agrarias gubernamentales, las cuales se ven muchas veces obligadas a remitir los asuntos a las asambleas comunales y a respaldar los acuerdos emanados de éstas, en virtud de la naturaleza jurídica de las tierras comunales que son reguladas por sus instancias de decisión y sus normas propias, en particular tratándose de comunidades de hecho. Un ejemplo es una resolución emitida por la Suprema Corte de Justicia en la que se desechó un recurso de amparo directo respecto a una sentencia emitida por el Tribunal Unitario Agrario del Estado de México que señala:

[...] es improcedente el reconocimiento de un mejor derecho para el uso, usufructo y disfrute en disputa [...] esa decisión descansa en la premisa fundamental de que está comprobado documentalmente que no existe un parcelamiento ni económico o de hecho, ni de derecho, en la comunidad [...] por lo que para que el Tribunal Agrario esté en condiciones de resolver sobre la litis, es menester que la asamblea general del núcleo de población se pronuncie al respecto, lo que no ha ocurrido. ${ }^{35}$

La separación entre propiedad y posesión de acuerdo con lo estipulado por el derecho positivo no corresponde con la concepción de las comunidades. Por ejemplo, en Huáncito consideran que el:
Dueño, es [...el que tiene] la posesión del terreno. Entonces, si no tiene la posesión, ahí también hay a veces problemas, de decir "pues tú supuestamente eres el dueño, pero nunca has estuvido [sic], has sido poseedor de ese terreno y si no presentas algún documento que te avale que eres el dueño pues, entonces, no eres el dueño" [...] Otra vez volvemos a la asamblea, entonces la asamblea dice, "está bien" $[\ldots] .{ }^{36}$

\section{En Ichán conciben que:}

La posesión es de quien la está trabajando, de quien vive ahí [...] La propiedad, pues, vendría siendo que ya tuviera sus documentos legales, pero aquí casi nadie los tiene; aquí hacemos unas minutas que dicen que ya es dueño [...] no lo puede vender, pero sí lo puede traspasar a un miembro de su familia. ${ }^{37}$

\section{Ideas finales}

Las prácticas comunales para la regulación de las tierras de las comunidades p'urhépechas de La Cañada revelan cierta autonomía en sus asuntos internos. Las instituciones agrarias no tienen mucha injerencia, incluso toman en cuenta las instancias de decisión y a las autoridades comunales con facultades para el reconocimiento de derechos sobre las tierras y para la solución de los conflictos internos, lo que es muy claro en las comunidades de hecho. En algunas comunidades de derecho se observa que, si bien el costumbre sigue siendo importante para regular la vida interna, cuando se trata de actos que requieren legalidad recurren a las instituciones agrarias, de modo que se lleva a cabo un uso estratégico y negociado del derecho agrario, lo que da lugar a una especie de "normatividad negociada".

Las autoridades comunales y sus atribuciones, la definición de membresías, las formas de acceso y transmisión de las tierras, así como sus mecanismos de regulación responden a una imbricación entre lo que establecen la ley y el costumbre, como resultado de procesos históricos de apropiación de, interpretación y resistencia a los distintos dispositivos jurídicos y 
formas de organización que se les ha tratado de imponer a lo largo del tiempo, con sus propias contradicciones y no libres de conflictos. Las membresías, y por ende los derechos de los comuneros, constituyen un campo de disputa. Las disposiciones establecidas por la legislación para el sujeto agrario no corresponden con la construcción social de comunero; ser comunero implica una "ciudadanía comunal", categoría que es mucho más amplia que la de sujeto agrario y no se circunscribe a los derechos agrarios, sino al goce de un conjunto de derechos definidos por la comunidad, siempre y cuando se cumpla con una serie de obligaciones.

Los mecanismos de regulación y la legitimidad de la autoridad comunal se han visto debilitados principalmente en las comunidades que han sido certificadas, en particular en las las que incluyeron sus zonasparceladas, estoes, con las políticasneoliberalesque buscan disolver lo que queda de los comportamientos de regulación comunal. Los comuneros han internalizado la idea de quelos certificados expedidosporlasinstituciones agrarias implican una especie de reconocimiento de la propiedad individual sobre las tierras, de manera que pueden disponer de ellas como mejor consideren, lo que entra en tensión con la concepción de propiedad comunal y con la posesión individual que prevalecían y que habían estado reguladas por las instituciones de gobierno comunal conforme el costumbre. En este sentido, las comunidades de hecho, al no poder ser certificadas, se encuentran protegidas de estas políticas que traen consigo una posible desarticulación, lo que les permite mantener sus gobiernos comunales y sus prácticas autonómicas, restando presencia del Estado en los asuntos que conciernen a sus tierras. Sin embargo, ambos tipos de comunidades enfrentan el asedio creciente de las agroempresas trasnacionales, que buscan arrendar grandes superficies en condiciones de total desventaja para los comuneros, en un contexto de abandono gubernamental para incentivar los cultivos tradicionales y de un apoyo a las iniciativas de control comunal sobre el destino de sus tierras. Lo anterior pone a prueba la cohesión social de las comunidades; como lo han venido haciendo a lo largo de su historia, de su capacidad de adaptación y resistencia dependerá su permanencia como colectividades.

\section{Notas}

${ }^{1}$ El trabajo de campo para la realización de este texto se llevó a cabo durante los años 2016 y 2017.

2 Registro Agrario Nacional. Disponible en: http:// datos.ran.gob.mx/filescd/dgos/ran_da_dgos_phina_ estructura_propiedad_social.xlsx (consultado el 2 de agosto de 2018).

3 Programa de Certificación de Derechos Ejidales y Titulación de Solares (PROCEDE) y Fondo de Apoyo para Núcleos Agrarios sin Regularizar (FANAR); este último sustituyó al primero, que cerró en 2006. Tiene los mismos objetivos, pere con un procedimiento abreviado.

${ }^{4}$ Constitución Política de los Estados Unidos Mexicanos, art. 107. Disponible en: http://www.diputados.gob.mx/ LeyesBiblio/pdf/1_240217.pdf (consultado el 1 de junio de 2017).

5 Suprema Corte de Justicia de la Nación (2000). "Comunidades agrarias de hecho y de derecho. Personalidad. Tesis histórica". Jurisprudencia Agraria 238256. Segunda Sala. Tomo III. Apéndice 2000. Séptima Época (consultado el 12 de julio de 2017).

6 Suprema Corte de Justicia de la Nación (1996). "Competencia agraria, comunidades de hecho, afectación de derechos de las. Corresponde conocer de esta a los tribunales agrarios al estar reconocidas y tuteladas directamente por la Constitución federal". Competencia 215/95. Pleno. Tomo III. Novena Época. Disponible en: https://sjf.scjn.gob.mx/sjfsist/Paginas/ DetalleGeneralV2.aspx?ID=200209\& $\&$ Clase=DetalleTesi sBL\&Semanario=0 (consultado el 12 de julio de 2017).

${ }^{7}$ Acuerdo para el cierre operativo PROCEDE en el Estado de Michoacán. DOF: 14 de junio de 2006. Disponible en: http://www.dof.gob.mx/nota_detalle.php?codigo=49 $11469 \&$ fecha=14/06/2006 (consultado el 13 de julio de 2017).

8 Respuesta por escrito de la Procuraduría Agraria, Delegación Michoacán, OF.PA/DM/000630/SDO0168/2016, 31 de agosto de 2016. 
${ }^{9}$ Desconozco el dato preciso a nivel estatal. Según datos de la Procuraduría Agraria en Michoacán, en "Asuntos de trascendencia que involucra comunidades" hay por lo menos nueve comunidades de hecho, todas de la región p’urhépecha. Respuesta por escrito, OF.PA/DM/000630/ SDO-0168/2016, 31 de agosto de 2016.

${ }^{10}$ Ley Orgánica Municipal del Estado de Michoacán de Ocampo. Última reforma publicada en el Periódico Oficial del Estado, el 1 de junio de 2017, tomo: CLXVII, número: 4l, cuarta sección. Disponible en: http://congresomich. gob.mx/cem/wp-content/uploads/LEY-ORGANICAMUNICIPAL-DEL-ESTADO-REF-01-DE-JUNIODE-2017.pdf (consultado el 30 de junio de 2017).

${ }^{11}$ Artículos 32, 35, 37, 38 de la Ley Agraria, 23 de febrero de 1992. Disponible en: http://www.pa.gob.mx/publica/ pa07bb.htm

${ }^{12}$ Artículos 17, 18 y 19 de la Ley Federal de Responsabilidad Ambiental, 7 de junio de 2013. Disponible en: http:// www.diputados.gob.mx/LeyesBiblio/pdf/LFRA.pdf

${ }^{13}$ Entrevista a don Argimiro, presidente del Comité de Bienes Comunales, 28 de febrero de 2017.

${ }^{14}$ Entrevista a Isaac Dávalos Alonso, representante del Comisariado de Bienes Comunales, 21 de febrero de 2017.

${ }^{15}$ Entrevista a Isaac Dávalos Alonso, representante del Comisariado de Bienes Comunales, 21 de febrero de 2017.

${ }^{16}$ Agradezco al Dr. Moisés Franco la información para la correcta escritura del término.

${ }^{17}$ En Ichán, Tacuro y Huáncito todavía existe el juez. Después de ocho años de decretar su desaparición, en 2013 el Poder Judicial ordenó a los síndicos recoger los sellos. Acompañados de la policía municipal y con amenazas exigieron a los jueces su entrega. Éste fue el caso de Zopoco, Huáncito se negó a entregarlo.

${ }^{18}$ Entrevista a don Guadalupe Santos, juez, 23 de junio de 2016.

${ }^{19}$ Ley Agraria, 23 de febrero de 1992. Disponible en: http:// www.pa.gob.mx/publica/pa07bb.htm

${ }^{20}$ Entrevista a don Argimiro, presidente del Comisariado de Bienes Comunales, 28 de febrero de 2017.

${ }^{21}$ Entrevista a Isaac Dávalos Alonso, representante del Comisariado de Bienes Comunales, 21 de febrero de 2017.
${ }^{22}$ Entrevista a don Adón, presidente del Comisariado de Bienes Comunales, 20 de febrero de 2017.

${ }^{23}$ Ley Agraria, 23 de febrero de 1992. Disponible en: http:// www.pa.gob.mx/publica/pa07bb.htm

${ }^{24}$ Entrevista a don Argimiro, presidente del Comisariado de Bienes Comunales, 28 de febrero de 2017.

${ }^{25}$ Entrevista a Isaac Dávalos Alonso, representante del Comisariado de Bienes Comunales, 21 de febrero de 2017.

${ }^{26}$ Ley Agraria, 23 de febrero de 1992. Disponible en: http://www.pa.gob.mx/publica/pa07bb.htm

${ }^{27}$ Entrevista a don Venustiano Baltazar, representante del Comisariado de Bienes Comunales, 15 de junio de 2016.

${ }^{28}$ Ley Agraria, 23 de febrero de 1992. Artículo 101. Disponible en: http://www.pa.gob.mx/publica/pa07bb. htm

${ }^{29}$ Entrevista a don Argimiro, presidente del Comisariado de Bienes Comunales, 28 de febrero de 2017.

${ }^{30}$ Entrevista a Isaac Dávalos Alonso, representante del Comisariado de Bienes Comunales, 21 de febrero de 2017.

${ }^{31}$ Entrevista a Isaac Dávalos Alonso, representante del Comisariado de Bienes Comunales, 21 de febrero de 2017.

${ }^{32}$ Entrevista a don Eduardo, presidente del Comisariado de Bienes Comunales, 17 de marzo de 2017.

${ }^{33}$ Entrevista a don Leobardo, Santiago, representante del Comisariado de Bienes Comunales, 20 de febrero de 2017.

${ }^{34}$ En el Valle de Zamora y regiones aledañas, varias agroempresas de capital nacional, estadounidense y chileno han rentado superficies considerables de ejidosy comunidades para la siembra de: arándanos, frambuesa y zarzamora. Productos destinados principalmente a la exportación. Michoacán produce el 98\% de la producción nacional y México ocupó el primer lugar de exportación mundial, durante el período de 2004-2006 (SEDAGRO, 2015).

${ }^{35}$ Suprema Corte de Justicia de la Nación. Amparo Directo en Revisión, 335/2015. Quejoso y recurrente. Disponible en:http://www2.scjn.gob.mx/ConsultaTematica/ PaginasPub/DetallePub.aspx?AsuntoID=176231 (consultado el 12 de julio de 2017). 
${ }^{36}$ Entrevista a Isaac Dávalos Alonso, representante del Comisariado de Bienes Comunales, 21 de febrero de 2017.

${ }^{37}$ Entrevista a don Leobardo Santiago, representante del Comisariado de Bienes Comunales, 20 de febrero de 2017.

\section{Referencias}

Broegaard, Rikke B. (2009). "Land Access and Titling in Nicaragua". En Development and Change, 40(1):149-169.

Franco Mendoza, Moisés (1997). La ley y la costumbre, en La Cañada de los Once Pueblos. Zamora, Michoacán: El Colegio de Michoacán.

INEGI (Instituto Nacional de Estadística y Geografía) (2010). Sistema para la Consulta de Información Censal 2010. México: INEGI. Disponible en: http:// gaia.inegi.org.mx/scince2/viewer.html.

Léonard, Éric, André Quesnel y Emilia Velázquez (2003). "Introducción. La regulación agraria en sus contextos: normatividad legal, prácticas de los actores y juegos de poder". En Éric Léonard, André Quesnel y Emilia Velázquez (coords.), Políticas y regulaciones agrarias: dinámicas de poder y juegos de actores en torno a la tenencia de la tierra. México: CIESAS/Institut de Recherche Pour Le Développement, pp. 9-38.

López Bárcenas, Francisco (2002). "Territorios indígenas y conflictos agrarios en México”. En Estudios Agrarios, 12(32): 85-108.
Nuijten, M. (2003). Power, Community and the State: The Political Anthropology of Organisation in Mexico. Londres y Sterling: Pluto Press.

Reyes Ramos, María Eugenia (2004). "Política agraria en Chiapas, atención a focos rojos". En Estudios Agrarios, 26:55-93.

Robles Berlanga, Héctor (2000). "Propiedad de la tierra y población indígena”. En Estudios Agrarios, 14:123-147.

SEDAGRO (2015). Plan Rector Zarzamora. Disponibleen: http://www.oeidrus.michoacan.gob.mx/index.php/ mas/publicaciondinamica/Sistema\%20Producto/ PLAN\%20RECTOR\%20\%20ZARZAMORA\%20 2015.pdf/detail (consultado el 30 de junio de 2017).

Sikor, Thomas y Christian Lund (2009). "Access and Property: A Question of Power and Authority". En Development and Change, 40(1):1-22.

Velázquez Hernández, Emilia (2006). Territorios fragmentados. Estado y comunidad indígena en el Istmo Veracruzano. México: CIESAS/El Colegio de Michoacán

Ventura Patiño, María del Carmen (en prensa). Conflictos agrarios en territorios indígenas en Michoacán. Programas de atención y tensiones políticas. México: Programa Universitario de Estudios de la Diversidad Cultural y la Interculturalidad-UNAM.

Torres Mazuera, Gabriela (2014). "La flexibilidad y rigidez del ejido como forma de tenencia de la tierra”. En Relaciones, 35(139):257-279. 
Cuadro 1. Situación agraria y certificación de las comunidades de La Cañada

\begin{tabular}{|c|c|c|}
\hline Comunidad & Carpeta Básica & $\begin{array}{c}\text { PROCEDE/FANAR } \\
\text { Hectáreas }\end{array}$ \\
\hline Tanaquillo & $\begin{array}{l}\text { RTBC** } \\
11 / 06 / 1965\end{array}$ & No \\
\hline Carapan* & No & No \\
\hline Acachuén* & $\begin{array}{l}\text { RTBC } \\
14 / 05 / 1954\end{array}$ & No \\
\hline Tacuro* & No & No \\
\hline Santo Tomás* & $\begin{array}{l}\text { RTBC } \\
18 / 09 / 2000\end{array}$ & $\begin{array}{l}\text { 29/11/2011 } \\
\text { Sup. parcelada: } 271 \\
\text { Sup. uso común: } 314 \\
\text { Reserva de crecimiento: } 108\end{array}$ \\
\hline Chilchota* & $\begin{array}{l}\text { RTBC } \\
18 / 01 / 2001\end{array}$ & $\begin{array}{l}\text { 14/07/2006 } \\
\text { Asentamiento Humano: } 491 \\
\text { Uso común: } 7565\end{array}$ \\
\hline Etúcuaro & $\begin{array}{l}\text { RTBC } \\
31 / 05 / 1989\end{array}$ & $\begin{array}{l}\text { 27/08/2005 } \\
\text { Sup. Uso común: } 779\end{array}$ \\
\hline Zopoco* & No & No \\
\hline Huáncito* & No & No \\
\hline Urén* & No & No \\
\hline Ichán* & No & No \\
\hline
\end{tabular}

* Estas comunidades cuentan con títulos virreinales, según información proporcionada por las autoridades comunales.

** RTBC: reconocimiento y titulación de bienes comunales.

Fuente: Padrón e Historial de Núcleos Agrarios (PHINA), Registro Agrario Nacional (disponible en: http://datos.ran.gob.mx/ filescd/dgos/ran_da_dgos_phina_estructura_propiedad_social.xlsx, consultado el 2 de agosto de 2018). 


\section{Cuadro 2. Conflictividad agraria en La Cañada}

\begin{tabular}{llr}
\hline \multicolumn{1}{c}{ Comunidad } & \multicolumn{1}{c}{ Conflicto de límites } & $\begin{array}{c}\text { Superficie en conflicto } \\
\text { (has apróx.) }\end{array}$ \\
\hline Ichán & Tacuro & 567 \\
Acachuén & Chilchota, Santo Tomás, Urén, Carapan, Tanaco, Zopoco & 1367 \\
Tanaquillo & Chilchota, *Huécato (por posesión) & 4225.32 \\
Carapan & Tacuro, Cherán, Acachuén & 524 \\
Chilchota & Tanaquillo, Urén, Santo Tomás, Acachuén, Huáncito, *Ocumicho, & 1153 \\
Huáncito & *Valle de Guadalupe, Etúcuaro & 687 \\
Tacuro & Chilchota, Santo Tomás & 887 \\
Santo Tomás & Ichán, Carapan & 1127 \\
Urén & Acachuén, Chilchota, Huáncito, Zopoco & 1010 \\
Zopoco & Chilchota, Acachuén, *Tanaco & 321 \\
Etúcuaro & Santo Tomás, Acachuén & 232 \\
\hline
\end{tabular}

*No pertenecen a La Cañada.

Fuente: Procuraduría Agraria, OF.PA/DM/000630/SDO-0168/2016, 31 de agosto de 2016.

\section{Mapa 1. La Cañada de los Once Pueblos}

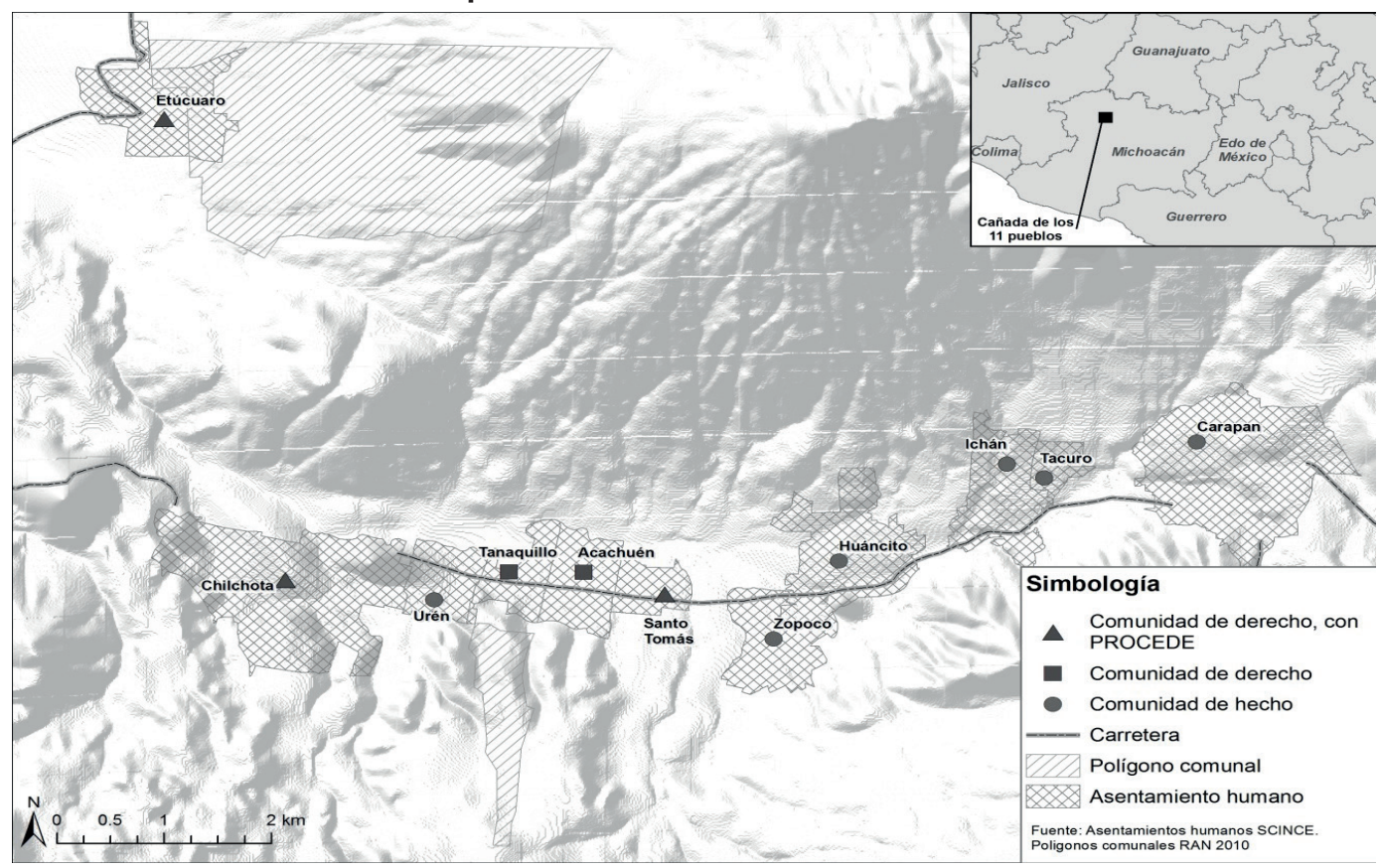

Fuente: Asentamientos humanos, INEGI (2010). 